\title{
Biological activities of a local plant $I$. viscosa from the Kabylia of Algeria
}

Nabila Chendouh Brahmi ${ }^{1}$, Asma Boudria ${ }^{1}$, Serverina Pacifico ${ }^{2}$, Simona Piccolella ${ }^{2}$, Lila Boulekbache ${ }^{1}$, Khodir Madani $^{1}$

${ }^{1}$ Laboratory of 3BS, Faculty of Life and Nature Sciences ,university of Béjaïa, 06000,Bejaia, Algeria.

${ }^{2}$ Departemant of Environmental, Biological, and Pharmaceutical Sciences and Technologies, University of Campania

Luigi vanvitelli, via Vivaldi 43,1-81100, Caserta, Italy.

Corresponding author Email: nabilabrami@yahoo.com

\section{Abstract}

The current article reports the in vitro biological activities and phytochemical studies using aqueous methanolic extract in plants fractions of Inula viscosa (I. viscosa). The plants were collected from the region of Algerian Kabylia in the wilaya of Bejaia. The phytochemical studies of the leaves of $I$. viscosa showed that the fraction of the plant extract proves as an active agent that can be used as an antioxidant or antileishmanial agent. Initially, the extract was prepared using aqueous methanol and then fractionated with ethyl acetate and butanol solvents. Total phenolic compounds, tannins, and flavonoids, of the hydromethanolic extract and their fractions were determined by the Folin-Cioalteu method, respectively, in gallic acid equivalent and aluminum chloride in rutin equivalent. The plants with their fractions were tested using the agar diffusion method for antimicrobial and antiparasitic activities against common bacteria (two visceral and skin Leishmania). Antioxidant activities were carried out using phosphomolybdenum, FRAP, and DPPH tests. Experimental results showed that the plant extract and fractions were rich in phenolic compounds and exhibited potent antioxidant, antimicrobial, and potency for moderate antileishmania activity. It was concluded that the plant $I$. viscosa is a promising medicinal plant.

Keywords: antioxidant, hydromethanolic phenolic compounds, extract, medicinal plant

\section{Highlights :}

- in vitro biological activities and phytochemical studies

- leaves of I. viscosa proves antioxidant and antileishmanial agents

- DDPH and FRAP test showed that plant is a rich resource of phenolic compounds

\section{Introduction}

Phenolic compounds are common plant secondary metabolites referred to as phytochemicals, act as antioxidants having significant beneficial effects on humans (Çalis et al., 2011; Nakilcioğlu, \& Hış1l, 2013). They can prevent the moieties and scavenge the free radicals. They also play vital roles in inhibiting the pathogenic processes linked to severe diseases like cancer, cardiovascular disease, macular degeneration, cataracts, and asthma, enhancing immune function (Akram et al., 2021). These compounds protect the cell damages by free radicals, released as byproducts of regular metabolism (Naz et al., 2021). Moreover, the antioxidant activities of the phenolic compounds from different plants are reported as antimicrobial agents against several pathogenic microorganisms (Stefanović et al., 2015; Türkyılmaz et al., 2013). Scientists currently investigate medicinal plants as an alternative to synthetic drugs due to increased microbial resistance. (Tavares et al., 2008). Therefore, the search of various plants as a source of antimicrobial agents or antioxidants compounds has become obligatory. Globally thousands of plants are well known used in traditional medicine due to their medicinal and therapeutic potentials. In these plants I. viscosa (L.) Aiton (syn. Dittrichia viscosa (L.) W. Greuter), commonly known as Inula, is an annual, herbaceous, perennial plant belonging to the Asteraceae family, widespread on the slopes of all the Mediterranean coastal regions (Seca et al., 2014). The plant is one of the few food sources available to honey bees, which bottled it, thanks to its abundant pollen production and long flowering. Inula provides unifloral honey in Europe. It represents a low-cost, efficient agent controlling varroosis in Apis mellifera colonies (Sofou et al., 2017). Similarly, it seems to have an active role in the cycle of auxiliary insects that control Bactrocera oleae, one of the main pests of olive groves. Indeed, the pest management activity of the plant is just one aspect that makes it unique. Traditional medicine brings in vogue its ability to exert health-promoting effects (e.g., anti-inflammatory, antipyretic, and antiseptic), and inula-based preparations are reported as valuable remedies. In Algeria I. viscosa leaf decoction was used to treat hypertension, diabetes mellitus (Tahraoui et al., 2007), and treat skin irritations of allergic origin (Passalacqua et al., 2007). The aims and objective of this article is the phytochemical screening of I. viscosa to prove that plants as an alternative to synthetic drugs to control different diseases

\section{Materials and methods}

\subsection{Plant collection}

The aerial parts of I. viscosa were collected in October 2018 from the Wilaya of Bejaia of Algeria and identified through the National Institute of Forest Research (Algeria). After collection and identification, plants were washed, dried, and stored in a dark place for further use.

\subsection{Preparation of extract}


Dried leaves of $I$. viscosa, were pulverized by a rotating knives homogenizer, and fifty gm $(50 \mathrm{~g})$ of this powder was extracted with hydro-methanol $(80 \%)$ at room temperature for 3 days. Then filtrates were obtained at $40{ }^{\circ} \mathrm{C}$ under reduced pressure through evaporation of methanolic extract by a rotary evaporator (IKA-RV 05-ST) and resuspended in water. Then different fractions were prepared using n-butanol $(n-B u O H)$ and ethyl acetate (EtOAc) solvents. The EtOAc, $\mathrm{n}-\mathrm{BuOH}$, and water fractions were removed under reduced pressure and dried at room temperature. The crude extract and fractions were stored at $4{ }^{\circ} \mathrm{C}$ in the dark for further analysis (Hammiche, \& Maiza, 2006).

\subsection{Phytochemical Screening of the plant}

The extract and fractions of I. viscosa were subjected to analyze the phytochemicals using Calis et al. [1] method for flavonoids, tannins, saponins, and alkaloids.

\subsection{Total phenols}

The total phenolic contents in the extract and fractions were determined using Folin-Ciocalteu colorimetric method (Rached et al., 2010). The reaction mixture was prepared by taking the sample $(1 \mathrm{mg} / \mathrm{mL})$ with $5 \mathrm{~mL}$ freshly FolinCiocalteu reagent diluted tenfold. After that $4 \mathrm{~mL}(75 \mathrm{~g} / \mathrm{L})$ of sodium carbonate was added (three replicates) and shaken, followed by color development at room temperature for $30 \mathrm{~min}$ at room temperature. The absorbance was recorded at $765 \mathrm{~nm}$ using the Shimadzu UV-VIS-1240 spectrophotometer. TPC expressed as mg gallic acid equivalent per mg of plant extract

\subsection{Total flavonoid content}

The aluminum chloride colorimetric method was used to determine the total flavonoid content described by Li et al. [13]. In this assay, an aliquot of the diluted sample $(1 \mathrm{mg} / \mathrm{mL})$ was added to $0.5 \mathrm{~mL}$ of $2 \% \mathrm{AlCl}_{3}$ methanol solution. After developing yellow colour in $1 \mathrm{~h}$, the absorbance was recorded at $420 \mathrm{~nm}$ at room temperature. Total flavonoid content was calculated as $\mathrm{mg}$ rutin equivalent per mg of extract. All samples were analyzed in triplicates.

\subsection{Determination of total tannin}

Total tannin was estimated by the gelatine method described by Mbaebie et al. [14]. About $200 \mathrm{mg}$ of gelatine was mixed with $2.0 \mathrm{~mL}$ of water and $2.0 \mathrm{~mL}$ of sample and allowed to stand for $15 \mathrm{~min}$ at $4{ }^{\circ} \mathrm{C}$ followed by vortex, and the resulting mixture was filtered through Whatman filter paper No $12.150 \mathrm{~mL}$ of the filtrate was diluted with water (up to $1.0 \mathrm{~mL}$ ). Then non-tannin phenolics were estimated by the procedure similar to that of total phenolic content estimation. The total tannin content of $I$. viscosa was determined by subtracting non-tannin phenolic from total phenolic content.

\subsection{In-vitro antioxidant assays and their potential}

\subsubsection{Determination of total antioxidant capacity}

The antioxidant activity of $I$. viscosa hydromethanolic extract and fractions was determined by the phosphomolybdenum method (Wang et al., 2008). About $0.4 \mathrm{~mL}$ of the methanolic extract $(1 \mathrm{mg} / \mathrm{mL})$ was mixed with $4 \mathrm{~mL}$ of reagent solution ( $0.6 \mathrm{M}$ sulphuric acid, $28 \mathrm{mM}$ sodium phosphate and $4 \mathrm{mM}$ ammonium molybdate). The total antioxidant capacity was expressed as $\mathrm{mg}$ equivalent to ascorbic acid per $\mathrm{mg}$ of extract. The tubes were capped and incubated in a water bath at $95^{\circ} \mathrm{C}$ for 90 minutes, followed by the samples cooling at room temperature. The absorbance of the green phosphomolybdenum complex was measured at $695 \mathrm{~nm}$. In the blank case, $0.4 \mathrm{~mL}$ of methanol was used in place of the sample in three replicates. The antioxidant activity was determined using a standard curve with ascorbic acid solutions as the standard. The average reading was used, and the reducing capacity of the extracts was expressed as mg of ascorbic acid equivalents per $\mathrm{mg}$ of extract.

\subsubsection{Ferric reducing antioxidant power (FRAP assay)}

The reduction of a ferric 2,4,6-Tris (2 pyridyl) 1,3,5-triazine (Fe3 +-TPTZ) to ferrous was applied to determine the FRAP assay in which coloured appeared (Fe2+-TPTZ) in the presence of extract. $2.7 \mathrm{~mL}$ of FRAP reagent was prepared according to Maksimović et al. [18]. Of $0.3 \mathrm{M}$ acetate buffer (pH 3.6), $10 \mathrm{mmol} \mathrm{TPTZ} \mathrm{solution} \mathrm{I} 40 \mathrm{mmol} \mathrm{HCl}$ and 20 mmol iron (III) chloride solution in proportions of $10: 1: 1(\mathrm{v} / \mathrm{v})$, respectively and $0.3 \mathrm{~mL}$ of extract $(0.1 \mathrm{mg} / \mathrm{mL})$ and expressed as ascorbic acid equivalents per mg of plant extract (Chouhan, \& Singh, (2011).

\subsubsection{DPPH method}

The antioxidant activity of the plant extract and the standards were determined based on the radical scavenging effect of the stable DPPH free radical (Rai et al., 2006). About $100 \mu \mathrm{L}$ of standard or extract and fractions were added to $2 \mathrm{~mL}$ of DPPH in methanol solution ( $100 \mathrm{mM})$ in a test tube, respectively, and incubated at $37^{\circ} \mathrm{C}$ for $30 \mathrm{~min}$. The absorbance of each solution was determined at $517 \mathrm{~nm}$ using a spectrophotometer. The $\mathrm{IC}_{50}$ value is the concentration of the sample required to scavenge 50\% DPPH free radical (Prieto et al., 1999).

\subsection{Antimicrobial activity}

\subsubsection{Microbial strains}

The antimicrobial activity of hydromethanolic extract and the fractions were individually tested against pathogen microorganisms, including Listeria monocytogenes (L. monocytogenes) ATCC 19195, Escherichia coli ATCC 25922. Pseudomonas aeruginosa(P. aeruginosa) ATCC 27853, Bacillus cereus (B. cereus) ATCC 14759 and Staphylococcus aureus(S. aureus) ATCC 25923. Bacterial strains were cultured overnight at $37^{\circ} \mathrm{C}$ in Mueller Hinton. 
The agar disc diffusion method was employed to determine the antimicrobial activity of the extract and fractions (Maksimović et al., 2005). Briefly, a suspension of the tested microorganism ( $0.1 \mathrm{~mL}$ of 108 cells per mL) was spread on the solid media plates. Filter paper discs of $5 \mathrm{~mm}$ diameter were impregnated with $15 \mathrm{~mL}$ of hydromethanolic extract and fractions $(40 \mathrm{mg} / \mathrm{mL})$, so $1 \mathrm{mg} /$ disc and placed on the inoculated plates. After remaining at ambient temperature for $30 \mathrm{~min}$, these plates were incubated at $37^{\circ} \mathrm{C}$ for $24 \mathrm{~h}$. The diameters of the inhibition zones were measured in millimeters.

\subsubsection{Determination of minimum inhibitory concentration}

Minimum inhibitory concentration was determined as the method developed by Taye and collaborator (Rai et al., 2006). All tests were performed in Mueller Hinton Broth. Bacteria were suspended in MHB to give a final density of $5 \times 105$ $\mathrm{cfu} / \mathrm{mL}$. Geometric dilutions, ranging from 1000 to $7.81 \mathrm{mg} / \mathrm{mL}$ of extract and fractions, were prepared, and discs were impregnated as cited in the previous section. Petri plates were incubated under normal atmospheric conditions at $37^{\circ} \mathrm{C}$ for $24 \mathrm{~h}$, and the minimum concentration that inhibited growth was considered the MIC value of the fraction.

\subsection{Antiparasital activity}

\subsubsection{Parasite culture}

Two strains of Leishmania were tested: Leishmania major (L. major) (LCO3) and Leishmania infantum (L. infantum) (LV20). They were maintained at $27{ }^{\circ} \mathrm{C}$ by sub-passages in RPMI-1640 medium (Gibco) containing $100 \mathrm{mg}$ of streptomycin/mL and $100 \mathrm{U}$ penicillin/mL supplemented with $10 \%$ fetal bovine serum (FBS).

\subsubsection{Antileishmanial activity}

The antiparasitic activity was investigated on leishmanial promastigotes culture in 96-well plates. Culture of L. major and $L$. infantum promastigotes $(2 \times 105$ parasite $/ \mathrm{mL})$ were added to each well. Two-fold serial dilutions of extract and

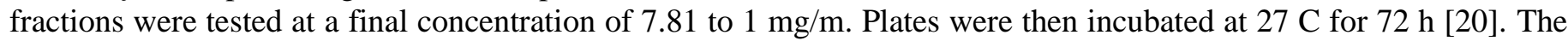
revelation of parasite viability was assessed by adding $10 \mathrm{~mL}$ of 3-[4,5- dimethylthiazole-2-yl (SIGMA, St. Louis, MO, USA) at $10 \mathrm{mg} / \mathrm{mL}$ to each well. After $4 \mathrm{~h}$ of incubation, the medium was removed, and formazan crystals were dissolved by adding $100 \mathrm{~mL}$ of DMSO. Absorbance was determined using an ELIS plate reader (Bio-EK) at 560nm.

Amphotericin B was applied as a positive control for all tests. Median inhibitory concentration (IC50) was obtained by fitting a sigmoidal Emax model (Celiktas et al., 2007) to a dose-response regression (Graph Pad Prism 4). The experiment was conducted in three replicates, and the mean was calculated from the $\mathrm{IC}_{50}$ values obtained for each experiment.

\subsubsection{Cytotoxicity assay and selectivity index}

Cytotoxicity was evaluated in murine macrophagic cells (Raw 264.7). Macrophages culture was maintained in RPMI1640 medium supplemented with $10 \%$ FBS in antibacterial and antifungal solution. Macrophages viability was controlled by microscopically counting after staining with $0.1 \%$ Trypan blue solution. Macrophages were initially dispatched on a 96 well culture plate at a 105 cells/well concentration then allowed to adhere overnight at $37{ }^{\circ} \mathrm{C}$ under $5 \% \mathrm{CO}_{2}$. The medium was then replaced by a fresh one containing $100 \mathrm{~mL}$ of extract. After $72 \mathrm{~h}$ of incubation at $37^{\circ} \mathrm{C}$, viability was estimated by the MTT technique (Celiktas et al., 2007). The selectivity index (SI) is a parameter defining the balance between cytotoxicity and biological activity of the compound, corresponding to the highest active concentration with no toxicity and expressed as the ratio IC50 macrophage/IC50 parasite. A SI value higher than 4 was considered adequate for parasites and safe for macrophages (Al-Musayeib et al., 2012).

\section{Results}

\subsection{Phytochemical screening}

Following phytochemical tests were performed on I. viscosa to ascertain the presence of polyphenols, alkaloids, flavonoids, terpenoids, and saponins. The yields of aqueous methanolic extract, ethyl acetate fraction, butanolic fraction, and water fraction were $31.7 \%, 2.34 \%, 2.98 \%, 10.3 \%$, respectively.

\subsection{Phenolic content}

Total phenolic, flavonoid, and total tannin content of I. viscosa of hydromethanolic extract and fractions were presented in Table 1. The total flavonoid content was assay by aluminum colorimetric method and total tannin with Folin Ciocalteu reagent after tannin precipitation with gelatine. The data showed in Table 1 indicated that the highest flavonoid and tannin content $240.77 \mathrm{mg}$ rutin equivalent $/ \mathrm{mg}$ and $318.4 \mathrm{mg}$ gallic acid equivalent/mg dry extract, respectively, were observed in butanolic fraction. The lowest content was $10.3 \mathrm{mg}$ rutin equivalent/ $\mathrm{mg}$ and $57.56 \mathrm{mg}$ gallic acid equivalent/mg dry extract, respectively, in the water fraction.

\begin{tabular}{|c|c|c|c|c|}
\hline Extract and fraction & Yield $(\%)$ & Phenolic content & Flavonoid content & Tannin content \\
\hline Hydromethanolic extract & 31,7 & $240,77 \pm 2,23$ & $121 \pm 6,23$ & $143 \pm 5,23$ \\
\hline Ethyl acetate fraction & 2,34 & $318,4 \pm 3,23$ & $144,6 \pm 4,23$ & $278,08 \pm 4,23$ \\
\hline Butanolic fraction $\quad \mathrm{H} 2 \mathrm{O}$ fraction & $\begin{array}{l}2,98 \\
10,3\end{array}$ & $\begin{array}{l}466,21 \pm 1,23 \\
132 \pm 0,23\end{array}$ & $\begin{array}{l}345,32 \pm 4,23 \\
23,45 \pm 1,23\end{array}$ & $\begin{array}{l}280,45 \pm 6,23 \\
57,56 \pm 2,23\end{array}$ \\
\hline
\end{tabular}

Table 1: Yield and total phenols, flavonoids, and tannins of hydromethanolic extract and fractions from I. viscose 


\subsection{Total antioxidant activity}

Results reported in Table (2) showed high antioxidant capacities of butanolic and ethyl acetate fractions (567.67 \pm 33.45$)$ and $(478 \pm 27.33) \mathrm{mg}$ is equivalent to ascorbic acid/mg, respectively. Extract with high concentration demonstrated an increase in the total antioxidant capacity for the first time as no report is available regarding the total antioxidant activity of $I$. viscosa extract and fractions.

\subsection{Radical-scavenging activity by DPPH assay}

In the current research, three different methods, phosphomolybdenum, FRAP, and radical-scavenging by DPPH assay, were used to measure the antioxidant activities of $I$. viscosa hydromethanolic extract and fractions. The $\mathrm{IC}_{50}$ values were found $5.76 \mathrm{mg} / \mathrm{mL}, 6.33 \mathrm{mg} / \mathrm{mL}, 6.65 \mathrm{mg} / \mathrm{mL}$ and $17.12 \mathrm{mg} / \mathrm{mL}$ in ethyl acetate, butanolic fractions, hydroethanolic extract and water fraction, respectively. $\mathrm{IC}_{50}$ of ethyl acetate fraction $5.76 \mathrm{mg} / \mathrm{mL}$ was less than standard $5.65 \mathrm{mg} / \mathrm{mL}$, which may be due to the high chelating capacities of this extract.

\subsection{Ferric reducing antioxidant power}

Results presented in Table (2) indicated that I. viscosa extract and fractions showed reducing power activity. The reaction was determined by forming the intense blue color complex; a higher absorbance value indicates the sample's showed more substantial reducing power, which follows the order like butanolic fraction $>$ ethyl acetate fraction > aqueous methanolic extract $>$ water fraction.

Table 2: Antioxidant activities of I. viscosa aqueous methanol extract and fractions.

\begin{tabular}{llll}
\hline Extract and fractions & \multicolumn{1}{c}{ PM } & \multicolumn{1}{c}{ FRAP } & DPPH assay $\mathrm{IC}_{50}$ \\
\hline Hydromethanolic extract & $344,56 \pm 12,5$ & $555,34 \pm 9,78$ & $5,67 \pm 11,32$ \\
Ethyl acetate fraction & $478 \pm 12,11$ & $690 \pm 6,2$ & $5,76 \pm 0,09$ \\
Butanolic fraction & $567,67 \pm 12,65$ & $899,77 \pm 009$ & $6,33 \pm 009$ \\
H2O fraction & $230,55 \pm 12,65$ & $270 \pm 009$ & $17,12 \pm 009$ \\
Ascorbic acid & - & $5,65 \pm 003$ & \\
\hline
\end{tabular}

\subsection{Antimicrobial activity}

The results obtained relating to the antimicrobial potential of the aqueous-alcoholic extract and the fractions against three Gram-positive bacteria and two Gram-negative bacteria are reported in Table (3), which showed substantial antimicrobial activities of the extract while minor variations, especially on L. monocytogenes observed in the hydromethanolic extract. The most important results were observed in the butanol fraction, which showed activity on both types of bacteria.

Table 3: Antibacterial activity of I. viscosa hydromethanolic extract and fractions using disc diffusion method

\begin{tabular}{lccccc}
\hline Microorganisms & \multicolumn{5}{c}{ Extract and fractions } \\
& Hydromethanolic-extract & Ethylacetate & Butanolic-fraction & Aqueous-fraction \\
\hline Bacillus cereus & $12(300)$ & $10(120)$ & 15 & 11 \\
Escherichia coli & 10 & 13 & $13(120)$ & 10 & \\
Pseudomonas Aeruginossa & NA & NA & NA & NA \\
Listeria Monocytogenes & NA & $20(35)$ & $20(35)$ & $22(65)$ \\
Staphylococcus aureus & NA & NA & NA & NA \\
\hline 3.
\end{tabular}

\subsection{Antileishmanial and cytotoxicity activity}

When tested, aqueous methanolic extract and fractions of $I$. viscosa aerial parts showed no antileishmanial activity, contrary to promastigotes of $L$. major and $L$. infantum except for ethyl acetate fraction. This one extract showed a moderate activity with $\mathrm{IC}_{50}$ values of $(224.10 \pm 2.32) \mathrm{mg} / \mathrm{mL}$ and $(190.43 \pm 1.65) \mathrm{mg} / \mathrm{mL}$, respectively. The fraction has been shown negligible cytotoxicity on macrophagic cells (Table 4) reported for the first time on antiparasitic activity of I. viscose from Algeria. Lack of antileishmania activity of aqueous methanol extract and leaf fractions of I. viscosa has been observed during the tests against the promastigotes of $L$. major and $L$. infantum except for the acetate fraction of ethyl acetate. This has moderate activity with the following values $\mathrm{IC}_{50}$ of $(223.87 \pm 1.32) \mathrm{mg} / \mathrm{mL}$ and $(188.87 \pm$ $2.23) \mathrm{mg} / \mathrm{mL}$, respectively. Also, the fraction gave negligible cytotoxicity on macrophage cells (Table 4).

Table 4: Antileishmanial activity of hydromethanolic extract and fractions of I. viscosa.

\begin{tabular}{|c|c|c|c|c|c|}
\hline \multirow[t]{2}{*}{ Extract and fractions } & \multicolumn{2}{|l|}{ IC50 } & \multirow[t]{2}{*}{ IC50 } & \multicolumn{2}{|c|}{ SI } \\
\hline & L. infatum & L. major & & L. infatum & L. major \\
\hline Hydromethanolic extract & NA & NA & - & - & - \\
\hline Ethyl acetate fraction & 188,87 & $\begin{array}{l}236,87 \\
\text { NA }\end{array}$ & $\begin{array}{r}678,76 \\
-\end{array}$ & $\begin{array}{r}7,76 \\
-\end{array}$ & $\begin{array}{r}3,40 \\
-\end{array}$ \\
\hline Butanolic fraction & NA & NA & - & - & - \\
\hline
\end{tabular}


Brahmi et al., 2021

$\begin{array}{llll}0,89 \pm 012 & 10,89 \pm 012 & 12,89 \pm 012 & 43,89 \pm 012\end{array}$

$\mathrm{H} 2 \mathrm{O}$ fraction

NA

$0,34 \pm 0,09$

Positif control Amphotericin B

50: Lethal Concentration $50 \mu \mathrm{g} / \mathrm{ml}$.

$\mathrm{IC}_{50}$ : Inhibitor concentration 50 $\mathrm{\mu g} / \mathrm{ml}$. LC50: Lethal Concen
SI: Selectivity index.SD: Standard deviation.NA: not active.

\section{Discussion}

The use of herbal drugs is now taking the place of modern medicine, including antibiotics, due to antimicrobial resistance. The WHO reports explained that at present, $80 \%$ of the world population now prefer to take herbal medicine for their health care (Mazid et al., 2012). Several plant species are now used as traditional medicines to treat various diseases such as cancer, coronary arteriosclerosis, and the aging processes (Bussmann et al., 2010). It was observed that fungal infections during the past several years have risen due to the upsurge in the immunocompromised population (e.g., organ transplant recipients and patients with cancer or human immunodeficiency virus infection/acquired immune deficiency syndrome). The fact was related to antibiotics and toxicity in case of prolonged treatment. Infectious diseases, particularly skin and mucosal infections, are common in most tribal inhabitants due to lack of sanitation, potable water, and awareness of hygienic food habits.

The diversity in phenols and polyphenols of $I$, viscose leaves was unraveled, applying sequential fractionation techniques on extracts. Flavonoids, alkaloids, saponins, tannins, and terpenoids were determined in this species, and the total phenolic levels were based on their chemical reducing capacity relative to gallic acid. Aerial parts extract, and fractions showed a high phenolic content from $(466.21 \pm 2.40)$ to $(132 \pm 1.87) \mathrm{mg}$ GAE/mg of extract in butanolic and water fraction respectively; however, levels of reducing compounds may react directly with the Folin-Ciocalteu method by overestimating the total phenolic content. The phenolic compounds are marked as radical scavengers linked to their hydrogen donating properties (Soltana et al., 2016; Obied et al., 2007). The DPPH free radical scavenging model evaluated the antioxidant activity relatively quickly, which receives either an electron or becomes a stable diamagnetic molecule. The reductive ability of antioxidants was measured as reducing power, was evaluated by the conversion of $\mathrm{Fe}^{+3}$ to $\mathrm{Fe}^{+2}$ in the presence of the leaves extracts (Gülçın et al., 2003), as antioxidants convert the $\mathrm{Fe}^{+3} / \mathrm{ferricyanide}$ complex to the $\mathrm{Fe}^{+2}$ form by donating an electron and appear yellow to green and blue (Chou et al., 2003). The ability of these extracts to reduce $\mathrm{Fe}^{+3}$ may be attributed to the hydrogen donating effect of phenolic compounds (Shahidi et al., 1992). It has been reported that phenolic compounds were the main antioxidant components, and their total contents were directly proportional to their antioxidant activity. Therefore, in this study, the presence of the flavonoids and phenols in all the tested extracts of $I$. viscose leaves might have contributed to the antioxidant activity. The modifications in results may be related to the chemical nature of the compounds present in the extracts (Shahidi et al., 1992) or various solvents used for the extraction (Li et al., 2009) and the differences in the sources and chemical nature of the compounds present in plant matrices (Shahidi et al., 1992).

The significant antioxidant activity was measured in ethyl acetate and butanolic fractions, which may be related to their high content of phenolic compounds, as reported earlier (Djeridane et al., 2006). The reducing capacity can significantly indicate its potential antioxidant activity, where a higher absorption indicates a higher ferric reducing power (Venkatachalam, \& Muthukrishnan, 2012). The phosphomolybdenum method reduces the Mo (VI) complex to Mo (V) with maximum absorption at $695 \mathrm{~nm}$. Polyphenols are the leading compounds contributing to antioxidant properties (Nithiyanantham et al., 2012). The ability of antioxidants to scavenge free radicals is related to the donation of hydrogen atoms or electrons; therefore, they play a significant role in human health to cure several diseases (Haider et al., 2011; Patel, \& Chu, 2011; Nunomura et al., 2006; Boskovic et al., 2011; Essid et al., 2015; Mailoa et al., 2014).

The plant extract and fraction were effective as new antibacterial agents, active against pathogens such as Bacillus cereus, Escherichia coli, Pseudomonas aeruginosa, and L. monocytogenes. Results showed that the butanol fraction was the active fraction to control the growth of bacteria as compared to other solvents; which showed the high contents of phenol in a fraction such as tannins which are excellent antimicrobial agents (Mailoa et al., 2014; Ruban \& Gajalakshmi, 2012), and in particular, flavonoids are known to be an effective antimicrobial agent against a wide range of microorganisms (Ruban, \& Gajalakshmi, 2012). The gram-positive L. monocytogenes were the most inhibited bacteria in most plant fractions. In comparison, Gram-negative bacteria are usually reported as multidrug-resistant against many antibiotics (Taye et al., 2011).

The extract and fractions of the I. viscosa plant were tested for their potential efficacy against Leishmania parasites using promastigotes from $L$. major and $L$. infantum. It was observed that the ethyl acetate fractions had an $\mathrm{IC}_{50}$ value> $100 \mathrm{mg} / \mathrm{mL}$, this activity was relatively low with also selectivity $(\mathrm{SI}=3.7)$ and $(\mathrm{SI}=4.52)$ (Duarte et al., 2016) than that of the positive control amphotericin with $\mathrm{IC}_{50}=(0.22 \pm 0.09) \mathrm{mg} / \mathrm{mL}$ and $(0.80 \pm 0.18) \mathrm{mg} / \mathrm{mL}$ on L. major and L. infantum respectively. No experimental data is available on a possible antileishmanial activity of the extract of $I$. viscosa. These results with non-existent or relatively modest anti-leishmanial effects in cultured promastigotes could be attributed to the preparation of solvents of a bioactive compound, or there is no synergistic effect between the 
phytochemicals in the extract or fraction, such as this result is found by the study of Duarte et al. in (2016) who demonstrated that the fraction of the aqueous extract of Thymus officinalis Roscoe was more active against in vitro promastigotes and in vivo amastigotes of Leishmania amazonensis compared to the extract (Duarte et al., 2016).

\section{Conclusion}

Phytochemical screening of $I$. viscosa concluded that this plant might act as an alternative to synthetic drugs to control different diseases in the future. The phytochemical studies of the leaves of I. viscosa showed that the fraction of the plant extract proves that it contains active agents that can be used as an antioxidant or antileishmanial agent.

\section{Acknowledgment}

The authors highly acknowledged the laboratory of 3BS, Faculty of Life and Nature Sciences, University of Béjaïa, 06000, Bejaia, Algeria and Departement of Environmental, Biological, and Pharmaceutical Sciences and Technologies, University of Campania Luigi vanvitelli, via Vivaldi 43,1-81100, Caserta, Italy.

Conflict of Interest: No potential conflict of interest was reported by the authors

\section{References}

Akram, J., Waseem, A., Azmat, R. (2021). Plants as a natural resource of bioactive compounds for drug formulation to control infectious diseases Journal Advances of nutrition science and technology, 1(1), 11-18.

Al-Musayeib, N. M., Mothana, R. A., Matheeussen, A., Cos, P., \& Maes, L. (2012). In vitro antiplasmodial, antileishmanial and antitrypanosomal activities of selected medicinal plants used in the traditional Arabian Peninsular region. BMC complementary and alternative medicine, 12(1), 1-7.

Boskovic, M., Vovk, T., Kores Plesnicar, B., \& Grabnar, I. (2011). Oxidative stress in schizophrenia. Current neuropharmacology, 9(2), 301-312.

Bussmann, R. W., Glenn, A., Meyer, K., Kuhlman, A., \& Townesmith, A. (2010). Herbal mixtures in traditional medicine in Northern Peru. Journal of Ethnobiology and Ethnomedicine, 6(1), 1-11.

Çalis san O, Polat AA. Phytochemical and antioxidant properties of selected fig (Ficus carica L.) accessions from the eastern Mediterranean region of Turkey. Sci Hortic 2011; 128: 473-8.

Celiktas, O. Y., Kocabas, E. H., Bedir, E., Sukan, F. V., Ozek, T., \& Baser, K. H. C. (2007). Antimicrobial activities of methanol extracts and essential oils of Rosmarinus officinalis, depending on location and seasonal variations. Food Chemistry, 100(2), 553-559.

Chou, S. T., Chao, W. W., \& Chung, Y. C. (2003). Antioxidative activity and safety of $50 \%$ ethanolic red bean extract (Phaseolus radiatus L. var. Aurea). Journal of food science, 68(1), 21-25.

Chouhan, H. S., \& Singh, S. K. (2011). Phytochemical analysis, antioxidant and anti-inflammatory activities of Phyllanthus simplex. Journal of Ethnopharmacology, 137(3), 1337-1344.

Djeridane, A., Yousfi, M., Nadjemi, B., Boutassouna, D., Stocker, P., \& Vidal, N. (2006). Antioxidant activity of some Algerian medicinal plants extracts containing phenolic compounds. Food chemistry, 97(4), 654-660.

Duarte, M. C., Tavares, G. S., Valadares, D. G., Lage, D. P., Ribeiro, T. G., Lage, L. M., \& Coelho, E. A. (2016). Antileishmanial activity and mechanism of action from a purified fraction of Zingiber officinalis Roscoe against Leishmania amazonensis. Experimental parasitology, 166, 21-28.

Essid, R., Rahali, F. Z., Msaadaa, K., Sghair, I., Hammami, M., Bouratbine, A., \& Limem, F. (2015). In vitro evaluation of anti-leishmanial and cytotoxic activities of Essential Oils in Tunisia. Ind Crops Prod, 77, 795-802.

Gülçın, İ., Oktay, M., Kıreçcı, E., \& Küfrevığlu, Ö. İ. (2003). Screening of antioxidant and antimicrobial activities of anise (Pimpinella anisum L.) seed extracts. Food chemistry, 83(3), 371-382.

Haider, L., Fischer, M. T., Frischer, J. M., Bauer, J., Höftberger, R., Botond, G., \& Lassmann, H. (2011). Oxidative damage in multiple sclerosis lesions. Brain, 134(7), 1914-1924.

Hammiche, V., \& Maiza, K. (2006). Traditional medicine in Central Sahara: pharmacopoeia of Tassili N'ajjer. Journal of ethnopharmacology, 105(3), 358-367.

Li, H. Y., Hao, Z. B., Wang, X. L., Huang, L., \& Li, J. P. (2009). Antioxidant activities of extracts and fractions from Lysimachia foenum-graecum Hance. Bioresource technology, 100(2), 970-974.

Li, H. Y., Hao, Z. B., Wang, X. L., Huang, L., \& Li, J. P. (2009). Antioxidant activities of extracts and fractions from Lysimachia foenum-graecum Hance. Bioresource technology, 100(2), 970-974.

Mailoa, M. N., Mahendradatta, M., Djide, N., \& Indonesia, A. (2014). Test of antimicrobial activity of tannins extract from guava leaves to pathogens microbial.

Maksimović, Z., Malenčić, Đ., \& Kovačević, N. (2005). Polyphenol contents and antioxidant activity of Maydis stigma extracts. Bioresource technology, 96(8), 873-877.

Mazid, M., Khan, T. A., \& Mohammad, F. (2012). Medicinal plants of rural India: a review of use by Indian folks. Indo Global journal of pharmaceutical sciences, 2(3), 286-304.

Mbaebie, B. O., Edeoga, H. O., \& Afolayan, A. J. (2012). Phytochemical analysis and antioxidants activities of aqueous stem bark extract of Schotia latifolia Jacq. Asian Pacific Journal of Tropical Biomedicine, 2(2), 118-124. 
Megdiche-Ksouri, W., Trabelsi, N., Mkadmini, K., Bourgou, S., Noumi, A., Snoussi, M., \& Ksouri, R. (2015). Artemisia campestris phenolic compounds have antioxidant and antimicrobial activity. Industrial Crops and Products, 63, 104113.

Nakilcioğlu, E., \& Hışı1, Y. (2013). Research on the phenolic compounds in Sarilop (Ficus carica L.) fig variety. Gida, 38(5), 267-74.

Naz, S., Rasheed, M.N., Jillani, M.I. (2021). Phytochemical characterization and evaluation of the antimicrobial and antioxidant activity of various fractions of Malva sylvestris (Pick-cheese) leaf extracts. Journal Advances of nutrition science and technology 1(2): 60-70.

Nithiyanantham, S., Selvakumar, S., \& Siddhuraju, P. (2012). Total phenolic content and antioxidant activity of two different solvent extracts from raw and processed legumes, Cicer arietinum L. and Pisum sativum L. Journal of food Composition and Analysis, 27(1), 52-60.

Nunomura, A., Castellani, R. J., Zhu, X., Moreira, P. I., Perry, G., \& Smith, M. A. (2006). Involvement of oxidative stress in Alzheimer disease. Journal of neuropathology \& experimental neurology, 65(7), 631-641.

Obied, H. K., Bedgood Jr, D. R., Prenzler, P. D., \& Robards, K. (2007). Chemical screening of olive biophenol extracts by hyphenated liquid chromatography. Analytica Chimica Acta, 603(2), 176-189.

Passalacqua, N. G., Guarrera, P. M., \& De Fine, G. (2007). Contribution to the knowledge of the folk plant medicine in Calabria region (Southern Italy). Fitoterapia, 78(1), 52-68.

Patel, V. P., \& Chu, C. T. (2011). Nuclear transport, oxidative stress, and neurodegeneration. International journal of clinical and experimental pathology, 4(3), 215.

Prieto, P., Pineda, M., \& Aguilar, M. (1999). Spectrophotometric quantitation of antioxidant capacity through the formation of a phosphomolybdenum complex: specific application to the Determination of vitamin E. Analytical biochemistry, 269(2), 337-341.

Rached, W., Benamar, H., Bennaceur, M., \& Marouf, A. (2010). Screening of the antioxidant potential of some Algerian indigenous plants. Journal of Biological Sciences, 10(4), 316-324.

Rai, S., Wahile, A., Mukherjee, K., Saha, B. P., \& Mukherjee, P. K. (2006). Antioxidant activity of Nelumbo nucifera (sacred lotus) seeds. Journal of ethnopharmacology, 104(3), 322-327.

Ruban, P., \& Gajalakshmi, K. (2012). In vitro antibacterial activity of Hibiscus rosa-sinensis flower extract against human pathogens. Asian pacific journal of tropical biomedicine, 2(5), 399-403.

Seca, A. M., Grigore, A., Pinto, D. C., \& Silva, A. M. (2014). The genus Inula and their metabolites: from ethnopharmacological to medicinal uses. Journal of ethnopharmacology, 154(2), 286-310.

Shahidi, F., Janitha, P. K., \& Wanasundara, P. D. (1992). Phenolic antioxidants. Critical reviews in food science \& nutrition, 32(1), 67-103.

Sofou, K., Isaakidis, D., Spyros, A., Büttner, A., Giannis, A., \& Katerinopoulos, H. E. (2017). Use of costic acid, a natural extract from Dittrichia viscosa, for the control of Varroa destructor, a parasite of the European honey bee. Beilstein journal of organic chemistry, 13(1), 952-959.

Soltana, H., Tekaya, M., Amri, Z., El-Gharbi, S., Nakbi, A., Harzallah, A., \& Hammami, M. (2016). Characterization of fig achenes' oil of Ficus carica grown in Tunisia. Food chemistry, 196, 1125-1130.

Stefanović, O. D., Tešić, J. D., \& Čomić, L. R. (2015). Melilotus albus and Dorycnium herbaceum extracts as source of phenolic compounds and their antimicrobial, antibiofilm, and antioxidant potentials. journal of food and drug analysis, 23(3), 417-424.

Tahraoui, A., El-Hilaly, J., Israili, Z. H., \& Lyoussi, B. (2007). Ethnopharmacological survey of plants used in the traditional treatment of hypertension and diabetes in south-eastern Morocco (Errachidia province). Journal of ethnopharmacology, 110(1), 105-117.

Tavares, A. C., Gonçalves, M. J., Cavaleiro, C., Cruz, M. T., Lopes, M. C., Canhoto, J., \& Salgueiro, L. R. (2008). Essential oil of Daucus carota subsp. halophilus: composition, antifungal activity and cytotoxicity. Journal of Ethnopharmacology, 119(1), 129-134.

Taye, B., Giday, M., Animut, A., \& Seid, J. (2011). Antibacterial activities of selected medicinal plants in traditional treatment of human wounds in Ethiopia. Asian Pacific Journal of Tropical Biomedicine, 1(5), 370-375.

Türkyılmaz, M., Tağı, Ş., Dereli, U., \& Özkan, M. (2013). Effects of various pressing programs and yields on the antioxidant activity, antimicrobial activity, phenolic content and colour of pomegranate juices. Food chemistry, 138(2-3), 1810-1818.

Venkatachalam, U., \& Muthukrishnan, S. (2012). Free radical scavenging activity of ethanolic extract of Desmodium gangeticum. Journal of Acute medicine, 2(2), 36-42.

Wang, H., Gao, X. D., Zhou, G. C., Cai, L., \& Yao, W. B. (2008). In vitro and in vivo antioxidant activity of aqueous extract from Choerospondias axillaris fruit. Food Chemistry, 106(3), 888-895. 